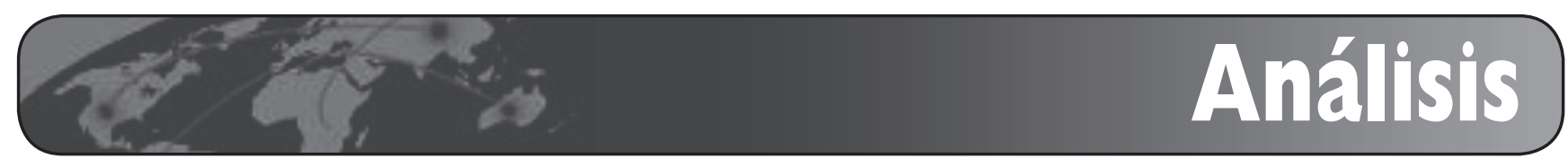

\title{
Modelos de gestión documental en las agencias de publicidad
}

\author{
Por Juan-Carlos Marcos-Recio, Juan-Miguel Sánchez-Vigil y María Olivera-Zaldua
}

\begin{abstract}
Resumen: La publicidad, como uno de los principales medios de comunicación, requiere de técnicas de investigación y documentación sin las cuales su eficacia quedaría en entredicho. Se hace un breve recorrido por la documentación publicitaria en España desde el punto de vista teórico y práctico. Además se analizan y se estudian los modelos de gestión documental que emplean las agencias, se explica y se perfila una definición de lo que se entiende por documentación publicitaria y se proponen aquellos elementos documentales que se han de utilizar en las campañas publicitarias y el funcionamiento de los centros de documentación.
\end{abstract}

Palabras clave: Publicidad, Gestión documental, Documentación, Agencias de publicidad, Investigación.

Title: Models for document management in advertising agencies: documentary elements of campaigns

Abstract: Advertising, one of

the leading communications media today, requires special techniques for research and documentation without which its effectiveness could be questioned. A brief study is made of advertising documentation in Spain from the theoretical and practical points of view. Then, the models for document management used in the agencies are studied and explained, and a definition of what is understood to be advertising documentation is drawn up. In addition, the documentary elements that should be used in the advertising campaigns and in the proper functioning of the documentation centres are proposed.

Keywords: Advertising, Documentary management, Documentation, Advertising agencies, Research.

Marcos-Recio, Juan-Carlos; Sánchez-Vigil, Juan-Miguel; Olivera Zaldua, María. "Modelos de gestión documental en las agencias de publicidad”. El profesional de la información, 2010, marzo-abril, v. 19, n. 2, pp. 175-183.

DOI: 103145/epi.2010.mar.08

\section{Introducción}

LA PUBLICIDAD FORMA PARTE de la sociedad de la información. Ha sido fiel com- pañera de los medios impresos, contribuyendo y apoyando su creación y mantenimiento y ha estado al lado de los medios audiovisuales (radio, cine, televisión y ahora internet) como refrendo informativo $y$ comercial. 
A pesar de casos como la reciente desaparición de la publicidad en Televisión Española o del rechazo que algunos organismos o personas le puedan tener, ha adquirido una gran importancia en la sociedad. También es relevante desde el punto de vista económico, porque la publicidad reactiva la economía y porque además aporta un importante valor en el producto interior bruto (PIB) (el 1,36\% en 2008) ${ }^{1}$. En definitiva, la publicidad es un referente informativo de primer orden para el consumidor cada vez que necesita comprar un producto.

El presente trabajo tiene por objeto situar brevemente la evolución de la documentación en el marco teórico de los estudios superiores en la universidad y su paso hacia el ámbito profesional, así como los modelos de gestión documental que emplean las agencias a la hora de preparar una campaña, sus recursos, fuentes y documentos de consulta más frecuentes.

\section{Implantación y evolución de la documentación publicitaria en España}

La documentación informativa es el tronco común del que han salido otras especialidades documentales como la de medios de comunicación y su subespecialidad en prensa, radio y/o televisión, cine y al mismo tiempo la de publicidad. De esta forma, todo el abanico de medios de comunicación dispone de una disciplina con el fin de dar servicio a los diferentes profesionales.

La implantación y puesta en práctica de la documentación ha sido desigual en cada medio. De todos ellos, el que menos ha avanzado es precisamente la publicidad, en parte por culpa de los propios documentalistas que no han sabido reconocer el valor que pueden aportar a esta profesión y, en parte, por los propios publicitarios que prefieren contratar los datos que necesitan a empresas externas antes que disponer de un centro propio de documentación.

\section{"El centro pionero en España en impartir estudios de documentación informativa fue la Facultad de Ciencias de la Información de la Universidad Complutense"}

El respaldo oficial a los estudios de documentación informativa en España se produce a comienzos de los años noventa. Ya con anterioridad existieron estos estudios en algunas facultades, como Ciencias de la Información de la Universidad Complutense, donde se impartía en las tres licenciaturas: periodismo, publicidad y relaciones públicas y comunicación audiovisual. Desde entonces y hasta la llegada del Espacio Europeo de Educación Superior (Eees), han formado parte de la troncalidad de estas disciplinas, si bien no en todas las facultades se ha ofrecido una especialización en documentación publicitaria como tal.

La Facultad de Ciencias de la Información de la Universidad Complutense fue también la primera en aplicar la documentación de forma especializada en la publicidad, como medio de comunicación y como desarrollo profesional, especialmente a partir de las publicaciones de los profesores que trabajaban en el citado departamento (López-Yepes, 1979; Caridad-Sebastián, 1979; García-Gutiérrez, 1981) $)^{2}$. El primero considera la documentación como una rama principal del saber, pero también centrado en la comunicación publicitaria: "los procesos documentales sólo cobran verdadera entidad cuando se aplican hic et nunc a una determinada parcela del saber, en nuestro caso la comunicación publicitaria". Por su parte, Caridad-Sebastián aplica el uso de los ordenadores a la búsqueda y recuperación de la información y los bancos de datos y presenta adelantándose a las tecnologías actuales "la recuperación de la documentación a distancia". Por último, García-Gutiérrez analiza y planifica un sistema de trabajo en los centros de documentación nacionales y regionales.

A comienzos de los años 80 del siglo pasado ya hay por tanto una actividad documental teórica, aunque no se refleja en la práctica, si bien algunas agencias de publicidad españolas ya utilizaban algunas técnicas de investigación. Basta con ver algunas de las revistas de la época como Control, IPMark o Publitecnia para darse cuenta de la importancia de estos temas. Las necesidades de información surgen porque el anunciante demanda mayores resultados y sobre todo, porque la agencia necesita los datos para presentar mejores propuestas comunicativas. En este sentido, la implantación y el avance de la documentación publicitaria en España es lo que permite después la utilización de elementos documentales en las campañas publicitarias.

El citado departamento de documentación se implicó de forma directa en la publicidad en una segunda etapa con los trabajos del profesor Fernando Martín (Martín-Martín, 1987). Sus aportaciones suponen no sólo un gran avance teórico, sino que además se introduce la documentación en la gestión publicitaria. Son tareas documentales sustentadas mediante empresas como EDIT que se encarga del control gráfico y cualitativo de televisión y para ello realiza trabajos documentales como la recopilación mes a mes de todos los spots que por entonces emitía TVE. Este fue el primer modelo de gestión documental para las agencias.

Con el avance de la publicidad en España durante los años 80, una 
de las grandes épocas creativas, avalada por premios importantes en los festivales internacionales y por el apoyo de empresas multinacionales que confían algunas campañas a los publicitarios españoles, la documentación también se beneficia de esta situación. Así, según señala Martín-Martín, algunas empresas que habían nacido en la década anterior alcanzan su verdadero auge. Se trata de Dym-Panel o Duplo/Triplo que elaboran trabajos documentales muy segmentados para aquella época. Las acciones documentales de entonces se basan en el seguimiento estadístico de las audiencias, lo que permite al anunciante conocer quién lee determinado periódico o revista, quién escucha un determinado programa y quién ve cada programa de televisión. Mucho más ambiciosa fue Duplo, ya que además hace un seguimiento de la publicidad exterior y comienza una etapa de colaboración con el centro de documentación del Estudio General de Medios/Odec-Unitec.

Pero además de los datos estadísticos la documentación trabaja en otros frentes. En estos años aparece otro centro de documentación importante, RePress, que también se dedica al seguimiento de la publicidad. Para ello realiza controles cualitativos y cuantitativos, de forma similar a como se hacen en la actualidad. RePress en realidad significa Recortes de Prensa y su finalidad era hacer un seguimiento a los medios escritos. Así, el documentalista analiza y recorta toda la publicidad de estos medios y los clasifica y ordena. Éste podría ser considerado otro modelo de gestión que se empleó también en los centros de documentación de periódicos, radio y/o televisión. Con posterioridad, Nielsen pasó a ser el socio mayoritario de RePress. A juicio de Martín-Martín (1987): "RePress/ Nielsen es un centro de documentación que solamente persigue un tipo de difusión documental referida a documentos numéricos o cuantita- tivos; sus informes controlan paso a paso las inversiones publicitarias realizadas por los anunciantes y las agencias en cada uno de los medios, y nos ofrecen una difusión numérica por meses, medios, soportes, sectores, productos y marcas".

Los años noventa pasaron prácticamente desapercibidos para la documentación aunque no para la investigación, que fue avanzando. Las agencias españolas sufrieron también un retroceso con respecto a la década anterior y apenas se produce información científica en el ámbito documental.

Una tercera etapa, que coincide con la actual, parte de algunos trabajos de otros profesores del mismo departamento y de otras facultades (Nuño-Moral; Marcos-Recio; García-Jiménez, 2004), algunos de los cuales siguen trabajando en este tema. Se producen por tanto trabajos de esta especialidad en los que se trata de dar un giro a la documentación en la publicidad y actualizar parte de sus contenidos. Así, se publican algunos artículos y trabajos relacionados con: hipermedia y publicidad (García-Jiménez, 1998), información y publicidad (Marcos-Recio, 1999), publicidad y relaciones públicas (García-Jiménez, 1999), manera de optimizar una campaña con recursos publicitarios (MarcosRecio, 2002), documentación, fuentes y publicidad (Malalana-Ureña, 2002; 2004), fuentes de información en publicidad y en comunicación audiovisual (Palomares-Perraut; Gómez-Camarero, 2002), gestión de la documentación en la publicidad y en las relaciones públicas así como estrategias documentales que emplean las agencias de publicidad (Marcos-Recio; García-Jiménez; Nuño-Moral, 2004), las tesis doctorales en publicidad (Martínez-Pestaña, 2004) $)^{3}$, los contenidos documentales y su relación con la educación (Marcos-Recio; SánchezVigil; Fernández-Fuentes, 2005), uso de la fotografía y los derechos de autor (Marcos-Recio; SánchezVigil; Villegas-Tovar, 2005), actuación del documentalista/planner en las agencias de publicidad (MarcosRecio; Sánchez-Vigil; VillegasTovar, 2007), uso de las fuentes de información al servicio de la publicidad, investigación y planificación (Marcos-Recio, 2008a), bancos de imágenes, fototecas y su aplicación en la documentación publicitaria (Marcos-Recio, 2008b), estrategias y perspectivas documentales en la información digital y como una estrategia informativa y documental actual (Marcos-Recio, 2008c) y algunas pautas para la creación de técnicas bibliográficas para el análisis documental en publicidad (Marcos-Recio, 2009). Como se puede apreciar, se trata de una publicación amplia y efectiva sobre la documentación en publicidad.

\section{"Con la crisis se han cerrado algunos de los centros de documentación que venían funcionando con regularidad"}

Sin embargo, siendo la década más próspera, los resultados finales están por validar. Todo el trabajo teórico terminó con la creación de centros de documentación en las agencias, y la realidad actual indica que ha habido un retroceso ya que con la crisis que experimenta la publicidad, no ajena de otras actividades, se han cerrado algunos de los centros que venían funcionando con regularidad.

\section{Gestión documental de las agencias: elementos documentales en las campañas}

Se entiende por documentación "el conjunto de las disciplinas (ciencias de la documentación) relacio- 
nadas con el estudio del documento como fuente de información para obtener nueva información, o una toma de decisiones, disciplinas, etc." (López-Yepes; Ros-García, 1993). Esta definición ayuda a precisar la importancia que tiene en la actualidad la gestión de la información dentro de la documentación, constituyéndose en una de sus principales tareas. Y además destaca otra parte importante de la documentación publicitaria como es el uso de las fuentes de información. El proceso final concluye cuando los datos que aporta la documentación se pueden convertir en gestión eficaz de la información que necesitan los profesionales de la publicidad.

Y la publicidad ¿qué finalidad tiene? ¿Cuál es su función? ¿Quién ejecuta sus tareas? ¿Qué hace la documentación para mejorar sus resultados? Respondiendo a estas preguntas se habrán perfilado las tareas documentales.

Se toman como punto de partida dos definiciones de publicidad que ayudan a situar este trabajo: "comunicación impersonal pagada por un anunciante identificado que usa los medios de comunicación con el fin de persuadir a una audiencia o influir en ella" (Wells; Burnett; Moriarty, 1996) y también: "un medio de difusión de ideas ajenas y una técnica de persuasión orientada a dar a conocer de forma positiva, laudatoria y plena la existencia de productos y servicios, procurando suscitar su consumo" (GonzálezMartín, 1996). En ambas definiciones el anunciante proporciona un producto y/o servicio con el fin de que una audiencia lo compre. Por tanto, la primera idea documental consiste en aportar datos sobre esa audiencia, pero también de los productos, de la competencia, en definitiva, de todos aquellos elementos que conforman la comunicación publicitaria.

Por último, se entiende por documentación publicitaria: "aquella ciencia que ofrece datos contrastados, precisos y complementarios al briefing ${ }^{4}$ y que permite desarrollar nuevas ideas para llevar a cabo una campaña publicitaria. Es también una herramienta que busca dentro de las fuentes documentales las informaciones que ya han formado parte de otras campañas" (Marcos-Recio; García-Jiménez; Nuño-Moral, 2004). Así pues, la documentación realiza una doble tarea en la publicidad: por un lado, previa, para aportar los documentos precisos a partir del briefing $\mathrm{y}$, por otra, analizar, clasificar y ordenar las campañas que va haciendo la agencia conservándolas para futuras consultas. Este sería el tercer modelo de gestión y el usado en la actualidad.

Conocido el marco de actuación de la documentación publicitaria, precisaremos cuáles son los elementos documentales de una campaña y las fuentes usadas con mayor frecuencia en las agencias.

\subsection{Elementos documentales de las campañas}

La mayoría de los procesos publicitarios se inician con el briefing. Si la agencia y el anunciante llevan años juntos, no siempre se precisa un documento base. Si no es así conviene recibir uno escrito. A continuación se estudia, se analizan sus objetivos y se pone en marcha el equipo de trabajo para ver si es factible la propuesta del anunciante. Para ello se inicia la primera tarea documental que se basa en aportar datos y análisis sobre la propuesta que acaba de hacer el anunciante. Si los datos avalan la propuesta se procede a realizar el trabajo en los diferentes departamentos de las agencias (planificación, creatividad, cuentas, etc.). En caso contrario, se comentará con el anunciante y se hará un contrabriefing.

Habitualmente una campaña de publicidad tiene una duración de casi un mes desde el briefing hasta que sale en los medios. Algunas se pueden hacer en menos días, sobre todo las de internet, pero la producción y realización de televisión requiere de más tiempo y preparación. Ese es el tiempo que tiene el documentalista para aportar datos a cada uno de los departamentos implicados en la campaña.

\section{Producto/servicio/idea}

La documentación trabaja fundamentalmente para conocer el producto que se va a presentar. En ocasiones es una idea o un servicio. Tradicionalmente esta función era sencilla porque los productos estaban claramente diferenciados. Con la sociedad de consumo los productos cada vez se parecen más y los anunciantes intentan presentar novedades para hacerlos más atractivos. En esta parte del trabajo publicitario, el documentalista ha de buscar informes, datos, análisis sobre el producto, productos similares de la competencia, etc., con el fin de que el creativo resalte aquellos aspectos que no proporciona la competencia o que justifican que ese producto cumple con unas características determinadas.

\section{"Al carecer de centro de documentación la mayoría de agencias de publicidad sólo disponen de algunas revistas y libros sobre su profesión"}

Por ejemplo, el gazpacho Don Simón (figura 1) se anuncia como: "alimento $100 \%$ natural, con las mejores hortalizas frescas, aceite de oliva virgen y bajo en calorías". El documentalista ha de buscar información sobre productos naturales, hortalizas frescas, etc., con el fin de dar ideas al creativo para hacer una comunicación más natural. En definitiva, el documentalista ha de 


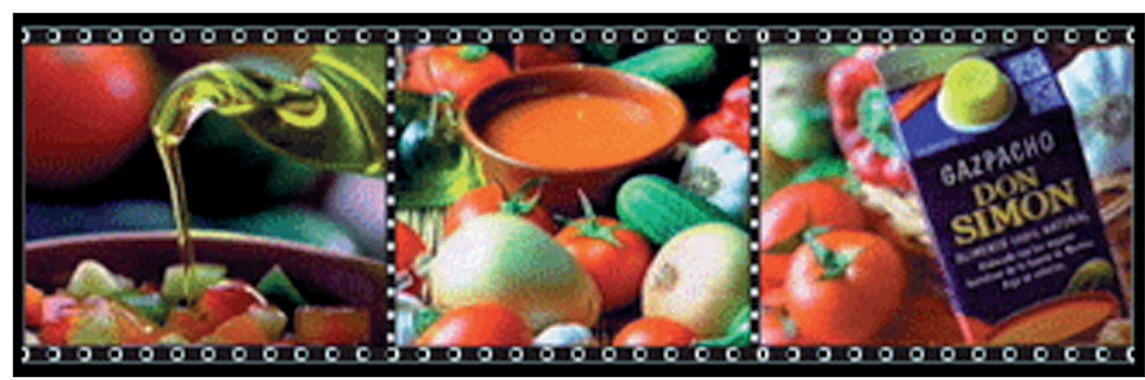

Figura 1. Fuente: marketing y publicidad Don Simon http://www.donsimon.com/

buscar una actitud positiva frente al producto para que así lo tenga también el consumidor, ya que éste puede aceptar, rechazar y/o ser indiferente ante el mismo.

\section{Presupuesto publicitario}

No siempre es fácil determinar el nivel económico que el anunciante asigna a un trabajo publicitario. Es cierto que las cifras son redondas, pero su distribución es realmente compleja. El presupuesto publicitario es el volumen total que el anunciante dedica a la campaña. Se pueden hacer grandes inversiones en publicidad, pero no siempre el rendimiento es alto. Lo normal es que gracias a la inversión publicitaria de un determinado producto (por ejemplo gazpacho Don Simón) se consiga un alto porcentaje de ventas y a su vez un beneficio para la empresa. Disminuir considerablemente la inversión puede suponer un grave riesgo en las ventas y en la imagen de marca de la empresa.

En este tema la documentación tiene menos campo de actuación, ya que la mayoría de los presupuestos son cerrados. Sí que es cierto que la documentación ha de preparar estudios de mercado y comprobar los resultados de otros presupuestos. Aunque en realidad no hay dos campañas iguales, algunos elementos de ciertas campañas son de aplicación en otras.

También el documentalista ha de buscar información sobre el precio, el propio y el de la competencia. Es un aspecto en el que cada vez se fija más el consumidor y un producto de similares características que competencia. Por eso, los documentalistas han de hacer un seguimiento de la misma, conocer sus fortalezas y debilidades y observar cada una de las actuaciones que realiza.

\section{Otras acciones documentales}

Teniendo amplios conocimientos del producto (razonados por el anunciante), el estudio de la competencia y contando con el presupuesto, cada uno de los departamentos de la agencia se pone en marcha para trabajar en el proceso creativo. Una vez que el departamento de cuentas ha realizado un presupuesto, en una primera etapa, y junto al departamento de creatividad, el documentalista aportará toda la información que ha conseguido sobre el producto y sobre los destinatarios de esa publicidad: los consumidores. El documentalista ha de conocer estudios que se hagan sobre los consumidores, bien segmentados y con diferentes particularidades. $\mathrm{La}$ razón última de la publicidad es el consumidor y cuantos más datos se tengan del mismo, más fácil será construir el mensaje publicitario.

Con todos esos datos se elabora un borrador en base a un storyboard o un script para que el anunciante se haga una idea. Si se acepta, el proceso se pone en marcha de manera definitiva. Entra en juego también el departamento de planificación de medios, quien de acuerdo con el de cuentas elabora la mejor estrategia para efectuar la compra de espacios donde irá insertado el anuncio. Paralelamente el departamento de creatividad irá trabajando en la idea creativa, en base a los documentos

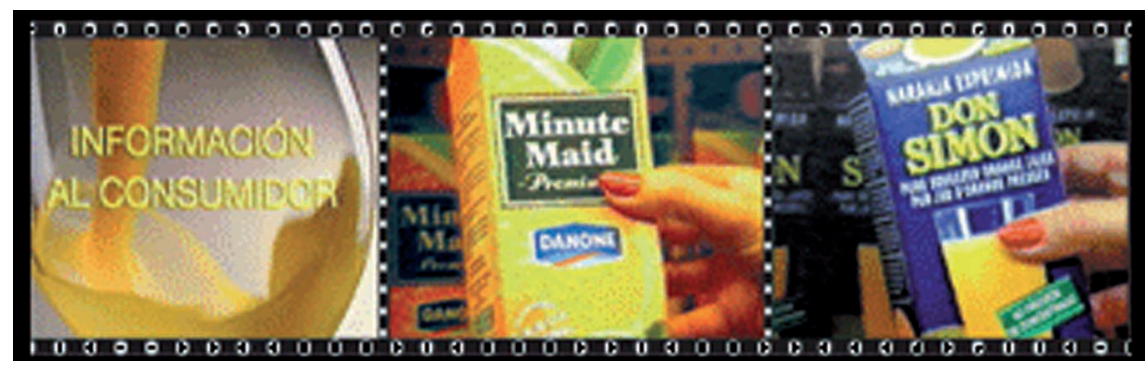

Figura 2. Fuente: marketing y publicidad Don Simon http://www.donsimon.com/ 
que le han ofrecido cuentas y planificación.

\section{"El departamento de investigación cumple funciones conjuntas con el de documentación y debería compartir nombre y funciones. Ese es el gran reto"}

En este recorrido, tanto si la agencia dispone de centro de documentación propio como si no, hay una serie de documentos cruciales que se han de manejar: datos y estudios de mercado, análisis de la competencia, análisis cualitativos y cuantitativos del mercado, conocimiento de las necesidades de los consumidores, etc., y todos estos datos son tareas del documentalista, que los irá entregando a cada uno de los departamentos para que avancen en su trabajo. En las agencias que no disponen de centro de documentación, suele asumir esa responsabilidad el planner si lo hay, o algún miembro del departamento de cuentas.

El proceso final se cierra con la idea creativa, que si es aceptada por el anunciante, se pasa a producción y realización. Una vez añadido el sonido y los trabajos de postproducción, la campaña está lista para ser vista en los medios de comunicación, principal soporte de la publicidad.

\subsection{Principales fuentes documen- tales de las campañas ${ }^{5}$}

La mayoría de las agencias de publicidad no disponen de centros de documentación como tal. Prefieren externalizar el trabajo y contratar los análisis que necesitan a empresas especializadas en el sector de la publicidad. En todo caso, esa razón no justifica la carencia de centros, ya que como se ha indicado antes, los documentalistas cumplen funciones esenciales en el proceso de creación publicitaria aportando datos del producto, el precio y la competencia, entre otros.

Las principales fuentes documentales para los publicitarios son aquellas bases de datos oficiales que les aportan informaciones sobre la competencia, su producto, el mercado, etc. Se trata de bases de datos como las del Instituto Nacional de Estadística o informaciones sobre los organismos del Estado, ya que muchas campañas tienen como anunciante al propio Estado.

Desde el punto de vista empresarial y para conocer datos del producto y de la competencia, se usan sitios de pago como Demoscopia, Gallup España, Instituto Doxa, Ipsos-Eco Consulting, Sigma Dos y Taylor Nelson Sofres. También destacan otras fuentes que investigan en medios de comunicación como InfoAdex, ETC Media, Arcemedia, Sofres, AIMC y OJD. Por supuesto, son valoradas y se conservan de manera documental las principales revistas del sector, que son una referencia a la hora de conocer algunos trabajos realizados por otras agencias, ya que suelen explicar una parte del trabajo publicitario efectuado en algunas campañas. Algunas ya disponen de un amplio fondo documental, incluidas bases de datos propias, pues llevan publicándose desde hace más de 40 años. Entre ellas destacan: Anuncios, Control, Campaña, Información de publicidad y marketing (Ipmark).

Las imágenes constituyen otra fuente de información. Gran parte de las agencias están suscritas a algún banco de imágenes para su trabajo publicitario. Destacan: $A G E$ Fotostock, Latin Stock, Getty Images, Corbis, etc., así como sitios de internet como Flickr, Dichis, AOL Photos, Fotolia, etc., que son un referente para algunos trabajos publicitarios.
Si se preguntara a los publicitarios cuál es su principal fuente de información, sobre todo tras la desaparición de algunos centros de documentación en las agencias, ya que la parte documental en tiempos de crisis parece ser la más débil, la mayoría responderían que internet, ya que el $90 \%$ de sus consultas las hacen en la Red y el resto con otros compañeros de la agencia, especialmente aquellas que son internacionales. Pues bien, nadie pone en duda el valor de internet, ya que como fuente resuelve muchas dudas, pero también plantea otras, que de forma sencilla podría haber resuelto un documentalista. Baste como ejemplo un error muy simple que habría sido resuelto por cualquier documentalista. El 10 de septiembre de 2008, La vanguardia publicó la información titulada: "Birmingham sí..., pero no Alabama" que contaba la historia de una campaña encargada por el ayuntamiento de Birmingham (Inglaterra) en la que se utilizaba como reclamo turístico una fotografía de Birmingham (Alabama). Pues bien, cuenta la información que "la persona encargada de ilustrar la campaña buscó en internet con la clave "Birmingham fotos", y copió una de ellas sin leer el texto y ni tan siquiera imaginar que pudiera ser de la ciudad de los Estados Unidos - cuya existencia no se sabe si desconoce o no, aunque por lo general los británicos son más viajados que los norteamericanos". Y lo que es peor, las autoridades se negaron a reconocer el error, con lo que la denuncia de un ciudadano vino a reflejar que se habían repartido 750.000 folletos que contenían errores. Así pues, internet es importante, pero más lo es contar con un documentalista para resolver las pequeñas y grandes necesidades de información.

En definitiva, la mayoría de las agencias de publicidad al carecer de centro de documentación, carecen de obras propias, a excepción de las revistas y algunos libros sobre 
la profesión, por lo que consultan la mayoría de las fuentes en internet, con las ventajas y limitaciones propias de la Red.

\section{Centros de documentación en las agencias de publicidad}

La principal fuerza que tienen las empresas es su información. Es su valor más importante y el más frágil. Para tomar cualquier decisión, por ejemplo una inversión, se necesita información actualizada, que aporte valor y que pueda utilizarse en el momento preciso. También en publicidad esta premisa es necesaria. Y si en otras empresas se tiene en cuenta la información y la documentación, aunque no haya un centro documental funcionando, en publicidad sucede lo mismo, pero el retraso en la creación de centros documentales es mayor.

¿Qué tareas ha de llevar a cabo un centro de estas características? ¿Por qué no hay más centros? ¿Dónde y quién tiene la responsabilidad de su creación? ¿Con qué fuentes ha de contar? ¿Puede ser rentable para la agencia tenerlo? Buscando las respuestas se plantean nuevos retos para la documentación publicitaria.

Afirma Fernando Martín que las tareas de un centro de documentación que trabaje en publicidad pasan por la recopilación y transmisión de las fuentes documentales $\mathrm{y}$ por facilitar todo tipo de documentación a los trabajadores de la agencia (Martín-Martín, 1987). Además, hay que trabajar en otro aspecto, los documentos (campañas) que genera cada trabajo y que hay que conservar para futuras acciones publicitarias. En definitiva, someter cada documento al análisis documental y conservarlo para posteriores consultas.

Es posible que la carencia de centros se deba al desconocimiento general que tiene la profesión publicitaria de lo que es un centro de documentación; de ahí la importancia de que en su formación superior conozcan bien qué es y para qué sirve la documentación. Se trata de demostrar que un centro puede generar recursos económicos para la agencia; o al menos, recortar la inversión en estudios y datos.

A la hora de crear un centro documental, las agencias presentan varios problemas (Marcos-Recio; García-Jiménez; Nuño-Moral, 2004):

- los clientes cambian;

- los productos que anuncian también;

- resulta difícil predecir quienes serán los clientes futuros;

- existen dificultades para actualizar la documentación debido a los factores anteriores;

- el espacio físico, ya que la mayoría de las agencias están situadas en lugares donde el espacio es caro;

- la confianza de los publicitarios es escasa;

- la misma sensación por parte de los documentalistas que apenas han creído en este sector;

- la responsabilidad documental de conservar su propio patrimonio, que apenas es interesante para los publicitarios.

Hay que señalar que casi todos los datos, análisis e investigaciones que hace una agencia, a excepción de internet, se compran a empresas externas. Incluso para pedir sus propias campañas que no han conservado y que pasados un par de años vuelven a necesitar. En este sentido, sí puede resultar rentable disponer de un centro con uno o dos documentalistas, pero hay que demostrar que los datos que van a aportar son interesantes para la creatividad, la planificación y/o la investigación.

Así, algunas agencias ya han probado que contar con un centro de documentación es viable y fac- tible: Tiempo BBDO y Contrapunto, o en su día McCann Erickson y Grey España, han trabajado campañas desde el ámbito documental. Bien es cierto que la actual crisis ha llevado al cierre de algún centro; sin embargo, en otros casos han estado funcionando y compartiendo documentos para varios clientes y productos. En su ausencia, el departamento de cuentas y los planners son los que se encargan de conseguir la información que requiere cada campaña.

\subsection{Departamento de documen- tación e investigación}

Las agencias de publicidad disponen de una estructura de trabajo muy bien planificada y ordenada. Sólo así se entiende que al mismo tiempo estén trabajando para diferentes anunciantes, diversos productos y para diferentes soportes en los que saldrá publicado el anuncio. La racionalidad del trabajo se hace efectiva en cada una de las etapas.

La mayoría de las agencias cuentan con los siguientes departamentos: cuentas, creatividad, planificación (estratégica y de medios), producción audiovisual, producción gráfica, tráfico, investigación, servicios generales y administración. No todas las agencias disponen de los mismos departamentos, en algunas están agrupados en producción tanto gráfica como audiovisual y otras externalizan algunas de estas funciones.

No siempre resulta fácil plantear esa relación epistemológica entre la documentación y la publicidad, pero sí es más fácil hacerlo con la publicidad, ya que hay una larga tradición en la investigación publicitaria. La investigación, como señalan algunos autores entre ellos González-Lobo y Prieto-DelPino, se hace en varias etapas del proceso publicitario, con estudios previos (del mercado), permanentes (a través de paneles y entrevistas), el producto y los estudios propiamente publicitarios. Por supuesto, 
la investigación en medios no debe faltar.

De todos los departamentos existentes en la agencia, los tres más relacionados con el departamento de documentación (gráfico 1) son: cuentas, planificación e investigación. Es necesario considerar con anterioridad qué parte de los trabajos de investigación se pueden realizar dentro del departamento de documentación, si bien la investigación de campo quedaría fuera de este servicio.

El departamento de cuentas, también llamado de servicio a clientes, se encarga de todas las acciones que responden a las necesidades del cliente. Su misión principal es informar al cliente de cómo se lleva a cabo la campaña y cuáles son los problemas que se han planteado. Además, supervisa todo el proceso. El departamento de planificación aporta datos sobre el mercado para conocer sus características, sobre la competencia para saber qué está haciendo, y qué tiene que hacer el cliente de la agencia, y sobre el producto. El departamento de investigación es imprescindible para cualquier trabajo publicitario. Sin él, los resultados serían menores. Este departamento trabaja en la investigación publicitaria, que sería aquella en la que puede intervenir más el documentalista, facilitando ideas, datos y campañas ya mostradas y la investigación de mercados, tanto cualitativos como cuantitativos, si bien este trabajo se suele encargar a los institutos de investigación. En definitiva, el departamento de investigación cumple funcione conjuntas con el de documentación y debería compartir nombre y funciones. Ese es el gran reto.

\section{Conclusiones}

Tras un breve recorrido por la documentación informativa y su vertiente publicitaria, tanto teórica como práctica, así como por algunos modelos de gestión, el estudio

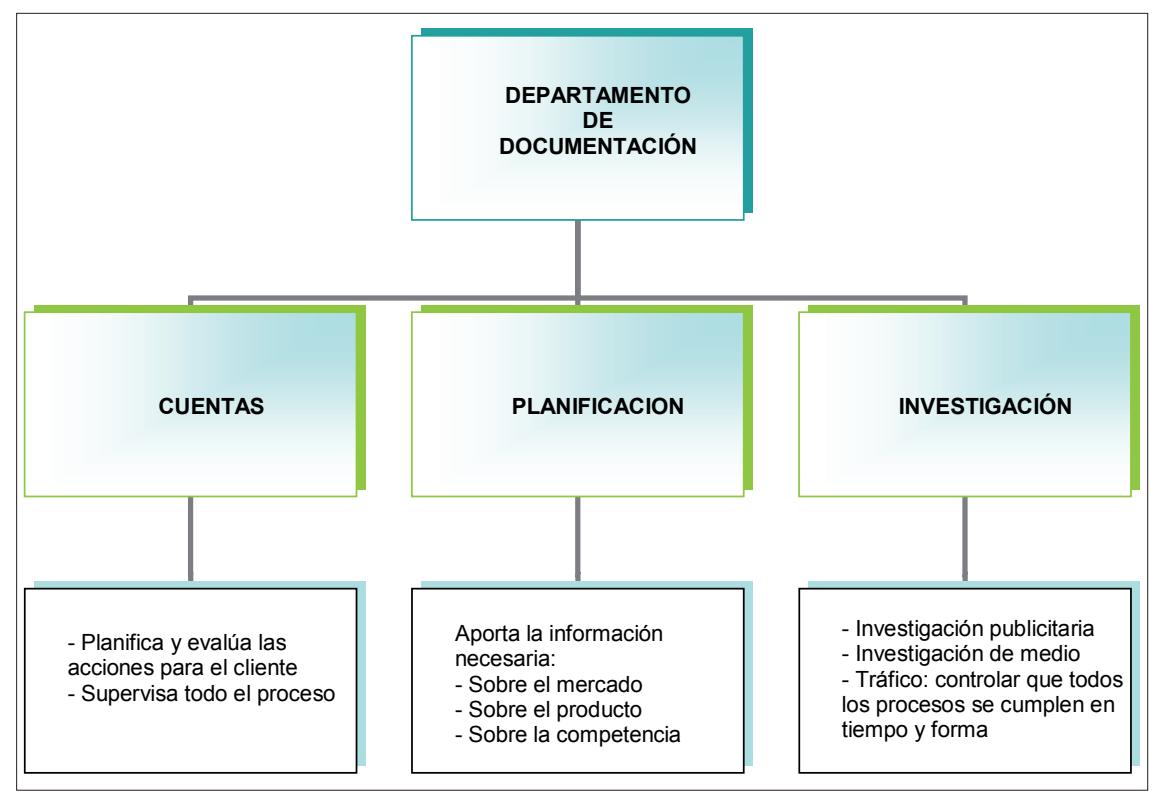

Gráfico 1. El departamento de documentación publicitaria

de las fuentes de información en publicidad, y de las tareas que han de llevar a cabo los departamentos, se concluye lo siguiente:

- La publicidad como acción comunicativa necesita de la información y de los datos de los estudios y análisis, y además es una actividad generadora de información.

- Si bien la crisis ha llevado a la desaparición de algunos centros de documentación en las agencias, es responsabilidad de los documentalistas reclamar un espacio de trabajo que es suyo por formación y tradición.

- Los centros de documentación de las agencias son rentables para las mismas.

- La publicidad es cada vez más emocional y de sentidos que racional, pero aun así necesita de los documentalistas para mejorar el trabajo final.

- Los costes de los centros de documentación en las agencias son siempre menores que los pagos efectuados a empresas externas por las funciones que éstos pueden desempeñar.

\section{Notas}

1. Estudio InfoAdex de inversión publicitaria en España 2009. http://www.infoadex.es/infoadex.asp

2. Los profesores José López-Yepes, Mercedes Caridad-Sebastián y Antonio García-Gutiérrez publicaron trabajos en la revista Publitecnia, aplicando su especialidad a la ciencia de la ciencia, el primero; la teledocumentación a la publicidad, la segunda; y el Sistema internacional de centros de documentación para la investigación en ciencias informativas (Comnet), el tercero.

3. En la actualidad está elaborando su tesis doctoral para recoger y analizar las tesis sobre publicidad y documentación.

4. Se considera el briefing como el documento base que entrega el anunciante a la agencia.

5. La revista $B i D$ publicó un artículo que recoge las principales fuentes de información en publicidad. http://www2.ub.es/bid/consulta_articulos. php? fichero $=11$ marco $2 . \mathrm{htm}$

\section{Bibliografía}

Alemany-Martínez, Lola. "La disciplina documentación informativa en los planes de estudio de la licenciatura de publicidad y relaciones públicas". En: Congreso universitario de ciencias de la documentación, 2000, v. 1, pp. 579-586. http://www.ucm.es/info/multidoc/multidoc/ revista/num10/paginas/pdfs/Lalemany.pdf

Caridad-Sebastián, Mercedes. "Nuevo acceso a las fuentes de la investigación publicitaria. La teledocumentación". Publitecnia: revista del Instituto Nacional de la Publicidad, 1979, n. 51-52, pp. 191-212.

Galdón-López, Gabriel (coord.). Teoría y práctica de la documentación informativa. Barcelona: Ariel, 2002. ISBN 9788434412934

Gámez-Fuente, María-José. “Aproximación a los últimos desarrollos comunicativos en publicidad audiovisual". En: Jornades de foment de la investigació, 2003.

http://www.uji.es/bin/publ/edicions/jfi6/publi.pdf

García-Gutiérrez, Antonio. "Estructura actual y perspectivas del sistema internacional de centros de documentación para la investigación de las 
ciencias informativas (Comnet)". Publitecnia: revista del Instituto Nacional de la Publicidad, 1981, n. 59

García-Gutiérrez, Antonio (ed). Introducción a la documentación informativa y periodística. Sevilla: MAD, 1999.

García-Jiménez, Antonio. "La documentación hipermedia en el ámbito de la publicidad y las relaciones públicas". Cuadernos de documentación multimedia, 1998, v. 6-7.

http://www.ucm.es/info/multidoc/multidoc/ revista/cuad6-7/garcjime.htm

García-Jiménez, Antonio. "La documentación de la publicidad y las relaciones públicas". En: García-Gutiérrez, Antonio (ed.). Introducción a la documentación informativa y periodística. Sevilla: MAD, 1999.

González-Lobo, M.-Ángeles; Prieto-Del-Pino, M.-Dolores. Manual de publicidad. Madrid: ESIC, 2009. ISBN 9788473566285.

González-Martín, Juan-Antonio. Teoría general de la publicidad. Madrid: FCE, 1996. ISBN 8437504171

López-Yepes, José. "La documentación como proceso informativo aplicable a la enseñanza y al ejercicio profesional del comunicador publicitario". Publitecnia: revista del Instituto Nacional de la Publicidad, 1979, n. 51-52.

López-Yepes, José. "Bases para la planificación de un centro de documentación en la agencia de publicidad". En: López-Yepes, José. Fundamen tos de información y documentación. Madrid: Eudema, 1989. ISBN 8477540543.

López-Yepes, José; Ros-García, Juan. ¿Qué es documentación?: teoría e historia del concepto en España. Madrid: Síntesis, 1993. ISBN 8477382131

Malalana-Ureña, Antonio. "Fuentes de información para el análisis de la publicidad. Las bases de datos publicitarias e internet". Cuadernos de documentación multimedia, 2004, n. 15. http://multidoc.rediris.es/cdm/viewarticle. php?id=12\&layout $=$ html

Malalana-Ureña, Antonio. "La documentación en publicidad”. En: Galdón-López, Gabriel. Teo ría y práctica de la documentación informativa. Barcelona: Ariel, 2002. ISBN 9788434412934.

Marcos-Recio, Juan-Carlos. La documentación electrónica en los medios de comunicación. Madrid: Fragua, 1999. ISBN 9788470741104.

Marcos-Recio, Juan-Carlos. "Desarrollo de aplicaciones documentales: ¿para qué sirve la información en una sociedad global?". Documentación de las ciencias de la información, 1999, v. 22, pp. 13-25. ISSN: 0210-4210.

http://www.ucm.es/BUCM/revistas/inf/ 02104210/articulos/DCIN9999110013A.PDF

Marcos-Recio, Juan-Carlos. "Evolución y desarrollo de la documentación en el campo publicitario: recursos para optimizar una campaña”. Do- cumentación de las ciencias de la información, 2002, v. 25, pp. 235-265. ISSN: 0210-4210.

http://revistas.ucm.es/portal/modulos. php? name $=$ Revistas2_Historico\&id $=D C I N \& n u$ $m=$ DCIN020211

Marcos-Recio, Juan-Carlos. "Estrategias documentales en agencias de publicidad". BiD: Biblioteconomia y Documentació, 2003, n. 11. ISSN 1575-5886

http://www2.ub.es/bid/consulta_articulos. php?fichero $=11$ marco $2 . h t m$

Marcos-Recio, Juan-Carlos. "PubliDocNet, una fuente de información en línea para la publicidad y la educación". Scire, 2005, v. 11, n. 2, pp 99-117. ISSN 1135-3761.

http://www2.ub.es/bid/consulta_articulos. php?fichero $=11$ marco $2 . h t m$

Marcos-Recio, Juan-Carlos. "Las fuentes de información al servicio de la publicidad. Investigación y planificación”. En: Martín-Requero, María-Isabel; Alvarado-López, María-Cruz (coords.). Nuevas tendencias en la publicidad de siglo XXI. Comunicación social, ediciones y publicaciones. Sevilla, 2008a, pp. 35-60. ISBN 9788496082519.

Marcos-Recio, Juan-Carlos. "La fotografía en la publicidad: archivos, bancos de imágenes y centros de documentación en el siglo XXI". En: Pacheco-Rueda, Marta (coord.). La publicidad en el contexto digital. Viejos retos y nuevas oportunidades. Sevilla: Comunicación Social, Ediciones y Publicaciones, 2008b, pp. 87-112. ISBN 9788496082717.

Marcos-Recio, Juan-Carlos. "Publicidad por pura pasión $(\mathrm{P}+\mathrm{p}+\mathrm{p}+\mathrm{p})$ ". Anuncios. Publicaciones profesionales, SAU, 13-19 de octubre de 2008c, n. 1255, p. 10. ISSN 0214-4905.

Marcos-Recio, Juan-Carlos. Técnicas bibliográficas para el análisis documental en publicidad: una propuesta básica. Sevilla: Comunicación Social, Ediciones y Publicaciones, 2009, (en prensa).

Marcos-Recio, Juan-Carlos; García-Jiménez, Antonio; Nuño-Moral, M.-Victoria. Gestión de la documentación en la publicidad y en las relaciones públicas, Madrid: Síntesis, 2004. ISBN 9788497561716

Marcos-Recio，Juan-Carlos; Sánchez-Vigil, Juan-Miguel; Fernández-Fuentes, Belén. "Gestión de los contenidos documentales en el ámbito de la publicidad y la educación”. Scire, 2005, v. 11, n. 2, pp. 79-98. ISSN 1135-3761.

http://ibersid.eu/ojs/index.php/scire/article/ view/1522/1500

Marcos-Recio, Juan-Carlos; Sánchez-Vigil, Juan-Miguel; Villegas-Tovar, Ricardo. "La imagen en la publicidad: la fotografía al servicio de la documentación publicitaria y los derechos de autor". Scire, 2005, v. 11, n. 2, pp. 119-132. ISSN 1135-3761.

http://ibersid.eu/ojs/index.php/scire/article/ view/1524/1502
Marcos-Recio, Juan-Carlos; Sánchez-Vigil, Juan-Miguel; Villegas-Tovar, Ricardo. "Los retos del documentalista/planner en la comunicación publicitaria". En: Jornadas Españolas de Documentación, E-información: integración y rentabilidad en un entorno digital. Fesabid 2007, pp. 363-372.

Marcos-Recio, Juan-Carlos; De-la-CuadraDe-Colmenares, Elena. "Nuevos formatos en creación publicitaria en televisión". En: IV Jornadas internacionales de jóvenes investigadores en comunicación. Fac. de Ciencias de la Comunicación, Univ. de Málaga; Asoc. Intl. de Jóvenes Investigadores en Comunicación (Aijic), 25 oct. 2007. ISBN 9788469082324.

http://eprints.ucm.es/7074/1/Nuevos formatos en_creacion_publicitaria.pdf

Martín-Martín, Fernando. La documentación publicitaria. Automatización del centro de documentación. Madrid: Unión Editorial, 1987. ISBN 8472092038

Martínez-Pestaña, María-Jesús. "La producción de tesis doctorales sobre temas publicitarios (1971-2001)". Documentación de las ciencias de la información, 2004, v. 27, pp. 237-267.

http://revistas.ucm.es/portal/modulos.php? name $=$ Revistas $2 \_$Historico\&id $=D C I N \&$ num $=D$ CIN040411

Palomares-Perraut, Rocío; Gómez-Camarero, Carmen. Fuentes de información de publicidad y comunicación audiovisual. Málaga: Universidad, 2002. ISBN 9788474969498.

Ramos, Rafael. "Birmingham sí..., pero no Alabama". La vanguardia, 10/09/2008.

http://hemeroteca.lavanguardia.es/preview/ 1991/05/28/pagina-7/73777073/pdf.html? search =birmingham\%20estados\%20unidos

Rocamora-Abellán, Rafael. "La metáfora en publicidad". Panacea: boletín de medicina y traducción, 2003, v. 4, n. 13-14, pp. 272-273.

http://www.medtrad.org/panacea/PanaceaPDFs/ Diciembre2003.htm

Sánchez-Vigil, Juan-Miguel; Marcos-Recio, Juan-Carlos; Villegas-Tovar, Ricardo. "Las cubiertas de los libros como mecanismo de marketing editorial". En: XIII Encuentros intls. sobre sistemas de información y documentación: Ibersid: revista de sistemas de información y documentación, 2008, n. 2, pp. 61-68. ISSN 1888-0967.

Welles, William; Burnett, John; Moriarty, Sandra. Publicidad. Principios y prácticas. México: Prentice Hall-Hispanoamérica, 1996. ISBN: 9688807974.

Juan-Carlos Marcos-Recio, JuanMiguel Sánchez-Vigil, María Olivera-Zaldua. Universidad Complutense de Madrid.

jmarcos@ccinf.ucm.es jmvigil@ccinf.ucm.es molizal@hotmail.com 